\title{
LAS TOPOGRAFÍAS MÉDICAS: REVISIÓN Y CRONOLOGÍA
}

\author{
Juan Casco Solís \\ Psiquiatra. De la Sociedad de Historia Filosofía de la Psiquistría \\ Servico de Salud Mental. Majadahonda (Madrid)
}

\section{RESUMEN}

Las Topografías Médicas constituyen la principal aportación bibliográfica de la medicina rural española a la Sanidad Pública. Son representantes cualificados de la línea de pensamiento médico que presta una detenida atención a los aspectos ambientales y sociales, en los procesos que afectan a la salud de las personas y de las comunidades. Son, por ello, un claro exponente de la mentalidad médica y socio-cultural de su respectivo tiempo. De ahí su interés histórico.

Este trabajo resume su evolución histórica y organiza su distribución cronológica.

\section{SUMMARY}

Medical Topographies are the main bibliographic contribution of Spanish rural medicine to Public Health.They are the qualified representatives of the medical line of thought that gives detailed attention to environmental and social aspects in the processes that affect the health of people and communities. They are for this reason a clear exponent of medical and socio-cultural mentality of the corresponding period. This explains their historical interest.

This work summarises their historical evolution and organises their chronical distribution.

SOCRATES: ¿Crees que es posible comprender digna y cabalmente la naturaleza del alma, sin la naturaleza del todo?

FEDRO: Si hemos de creer a Hipócrates, el discípulo de Asclepiades, ni siquiera la del cuerpo puede entenderse sin ese método. Platón. Fedro. 270 c.

\section{INTRODUCCIÓN}

Las Topografías Médicas ( en adelante T. M. ), son estudios de lugares geográficos concretos y de sus poblaciones, que se abordan desde una perspectiva higiénico-sanitaria y que comprenden, por regla general, la descripción física del punto - situación, clima, suelo, hidrografía - y la del entorno biológico — flora y fauna-; los antecedentes 
históricos, el temperamento físico y el carácter moral de sus habitantes, las costumbres, las condiciones de vida, los movimientos demográficos, las patologías dominantes y la distribución de las enfermedades. Y todo ello abordado con el fin de promover medidas para prevenirlas y remedios para tratarlas y mejorar el estado de salud de los individuos.

En nuestro país, la expresión «Topografía Médica» está amplia y suficientemente acreditada, aunque a veces se haya utilizado también, indistintamente, la de «Geografía Médica» ${ }^{1}$. Sin embargo, la mayoría de los autores han sido partidarios de utilizar esta última expresión -más rara ha sido la de «Corografía», de «joros», lugar, región- para el estudio de la distribución de enfermedades en territorios geográficos más amplios que el de lugares, términos municipales o comarcas, y geográficamente bien definidos (la «meseta central», por ejemplo, o «el Valle del Ebro», etc.) e incluso para territorios nacionales y aún subcontinentales, reservando para el estudio de un punto concreto el de «Topografía Médica»².

La producción de T.M. se ha desarrollado en España a lo largo de dos siglos, desde los años centrales de siglo XVIII hasta mediados del siglo XX. Este caudal ha constituído una de las más copiosas aportaciones realizadas al conjunto del movimiento higiénico-sanitario de nuestro país. Su contribución ha sido evaluada, cuantitativamente, como la cuarta parte de la producción bibliográfica global de las obras publicadas sobre Higiene entre 1.800 y $1936^{3}$.

Desde un punto de vista cualitativo, las T.M. ofrecen. también, a mi entender, un gran interés teórico y epistemológico. Como más adelante comentaré, las T.M. dan ocasión para poder observar «en vivo», la presencia y permanencia de una de las grandes corrientes del pensamiento médico que, viniendo desde las profundidades originarias, se ha mantenido a lo largo de los siglos — con mayor o menor fuerza según qué épocas- atravesando modas, escuelas y sistemas, como una invariable. Es la línea de pensamiento que podríamos llamar «ambientalista» - protocatárctica, en la terminología galénica - equilibrada en este caso, por la consideración de las condiciones internas, constitucionales y temperamentales de los individuos. Es por esto

1 Parece ser que fue el médico militar francés J. Ch. BoudiN (1.803-1.867) quien utilizó por primera vez este término: Essai de Géographie médical (Marsella, 1.843), en el contexto de la colonización de Argelia.

2 WeYler y LAVIÑa, F. (1.808-1879), también médico militar, en su Topografía físico-médica de las islas Baleares y en particular de la de Mallorca, (Palma, 1.854, pág. 13 ), dice lo siguiente:

«Siempre que el estudio de la medicina en general se hermanase con el de la tierra, denominaría a dicha ciencia Geografía médica reservando para un punto dado, el de topografía, o mejor Geo-Topografía médica».

Citado por Luis Urteaga en: «Miseria, Miasmas y Microbios. Las Topografías Médicas y el estudio del medio ambiente en el siglo XIX». Cuadernos Críticos de Geografía Humana, Univ. de Barcelona. No 29, Sept. 1.980, pág. 25.

3 URTEAGA, L. O.c., pág. 23 


\section{LAS TOPOGRAFÍAS MÉDICAS: REVISIÓN Y CRONOLOGÍA}

por lo que las T.M., al dirigir una mirada omnicomprensiva, de intencionalidad organizativa del espacio exterior, se han erigido en representantes cualificados de una concepción integradora, de un modelo holístico de pensamiento, a la hora de encarar los procesos físicos, biológicos y sociales referentes a la salud y a la enfermedad ${ }^{4}$.

Pese a ello, entiendo que aún no han sido estudiadas las T.M. con la profundidad y minuciosidad que merecen ${ }^{5}$, ni se han tenido demasiado en cuenta el enorme caudal de datos de todo tipo que contienen. Datos relevantes para entender el desarrollo del movimiento higiénico y sanitario de los últimos siglos, la penetración de los modelos de enfermedad y la difusión del pensamiento médico por las diversas zonas geográficas según los diferentes escalones asistenciales. Las T.M. constituyen, por otra parte, a mi juicio, la aportación más valiosa y genuina de los médicos rurales españoles al progreso de las ciencias de la salud

\section{ANTECEDENTES}

Muchas de las T.M. presentadas a los concursos promovidos por las Fundaciones de las Academias de Medicina - y que se guardan en sus archivos como manuscritos anónimos - aparecen bajo lemas alusivos al mismo Hipócrates ${ }^{6}$ o bien a la tradición médica que él representa ${ }^{7}$. Con ello se quería testimoniar, evidentemente, el carácter de continuadora de dicha tradición que tenían sus propias topografías, muy especialmente con la línea de pensamiento que arranca del tratado Sobre Aires, Aguas y Lugares.

En efecto, esta obra, una de las más célebres del corpus hipocrático, fué atribuída, desde siempre y de forma unánime por todos los expertos, al propio Hipócrates. Pero para las T.M., este tratado significa algo más que el de ser un simple antecedente. El tratado Sobre Aires, Aguas y Lugares significa para la historia de la Medicina no sólo el punto de partida de la tradición médica ambientalista y «meteorologista»; es además el primer intento de explicación científica que trata de relacionar la influencia

\footnotetext{
4 Buena parte de los expertos en medicina hipocrática afirman que la obra que Platón tenía en la cabeza cuando escribió esta parte del Fedro — que he citado al frente de este trabajo- fué precisamente el tratado Sobre Aire, Aguas y Lugares. Véase a este propósito la discusión recogida por Carlos García Gual en la Introducción General a los Tratados Hipocráticos. Tratados Hipocráticos, T.I Biblioteca Clásica Gredos. Ed Gredos, Madrid, 1.983., págs. 32 y sgtes.. Esta discusión está también recogida por J.A. López Freire en el estudio preliminar a Sobre aires, Aguas y Lugares, del T.II de la misma colección editorial, Madrid, 1.986, pág 19 y sgtes.

5 A mi entender, el mejor estudio sobre las T.M. españolas sigue siendo el ya citado de L. Urteaga.

6 Es el caso, por ejemplo, de las T.M de Lena (1.907), Majadahonda, (1.908), Colunga, (1.933) y Pravia (1.933) que encabezaban sus lemas con el nombre de Hipócrates.

7 Entre otras, las T.M. de Jerez de la Frontera (1.901), Hondonada de Campos (1.918), Sierra de Guadarrama (1.936) y Guadalix (1.953), recogen sus lemas inspirándose en los conceptos contenidos en Sobre Aires, Aguas y Lugares.
} 
del medio ambiente sobre las enfermedades y sobre los caracteres individuales. Puede también ser considerada esta obra como el origen de los discursos sobre psicología diferencial y comparada ${ }^{8}$.

Naturalmente, no es esta obra el único precedente de las T.M.

El Dr. J.B. Peset y Vidal señalaba en su famoso estudio sobre Valencia ${ }^{9}$ una «topografía médica» de Zaragoza atribuída a Benjamín de Tudela, escrita en el siglo XII y publicada en 1.575, y el ilustre historiador de la medicina D. Antonio Hernández Morejón, — también él autor de una «Topografía Médica de Menorca»10_, en su monumental Historia Bibliográfica de la Medicina Española, publicada en 1842, seis años después de su muerte, se lamentaba en términos amargos de esta forma:

«Así que siendo la España una de las naciones cuyos médicos cultivaron este ramo antes que los estranjeros, como lo prueban el Judío de Toledo médico de Fernando IV que escribió la topografía de Castilla; Juan de Abiñon, la de Sevilla; Castellano Ferrer la de Murcia; Cisneros la de Méjico; San Juan y Domingo, la de Aragón; Casal, la de Asturias; Unanue, la de Lima; y Piquer la de Valencia, apenas se halla hoy en nuestra Península quién escriba algo sobre este objeto» ${ }^{11}$.

8 Como es sabido, la última parte del tratado está dedicada íntegramente al estudio comparado de Europa y Asia, relacionando las características físicas y morales de sus habitantes con las condiciones telúricas y climatológicas de los respectivos territorios geográficos.

9 Peset y Vidal, J.B. (1878). En su Topografía Médica de Valencia y su zona, de, aporta este precedente, recoge los de Hernández Morejón, e incluye el testimonio de Luis de Lemos, médico portugués del siglo XVII y uno de los primeros críticos de Hipócrates, sobre la necesidad de tener en cuenta las condiciones meteorológicas: «No puede ser buen médico el que al pulsar no alce los ojos al cielo».

10 Desconocemos la fecha exacta de la publicación de esta T.M titulada Historia natural y médica de Menorca, pero el autor debió elaborarla durante su destino en la isla, como médico militar, entre 1.804-1.806.. El escocés George Cleghorn, había escrito también poco antes, durante el período de dominación inglesa de la isla un Tratado de las enfermedades de Menorca.

11 Juan de Aviñón: Sevillana Medicina que trata del modo conservativo y curativo de los que habitan en la muy insigne ciudad de Sevilla, la cual sirve y aprovecha para cualquier otro lugar de estos reynos. Es obra de 1.393 que no fue impresa hasta 1.547, con el añadido: Obra antigua digna de ser leída. Va dirigida al ilustrísimo cabildo de la misma ciudad.

* Cisneros, D. Sitio, naturaleza y propiedades de la ciudad de Méjico. Méjico, 1.618.

* SAN JUAN Y DOMINGO, N.F. 1.686.

* CASAl, G. Historia Natural y médica del Principado de Asturias. Madrid, 1.762.

Casal estudió en Alcalá de Henares y pasó luego a ejercer en Somolinos entre 1.706 y 1.717. Ese año se trasladó a Madrid donde enfermó. Para tratar de curarse se instaló en Oviedo. En sus tiempos, en todo el principado de Asturias sólo había cinco médicos: dos en Oviedo y uno en Villaviciosa, Gijón y Avilés Este dato nos permite entrever lo excepcional, minoritario y restringido que debió ser en nuestro país el acceso a la medicina científica, y por contra, el enorme peso que ha tenido la medicina popular.

*A Andrés Piquer le atribuye Hernández Morejón una T.M. de Valencia;sin embargo el Dr. Peset y Vidal no la encuentra en el registro general de sus obras.

*UNANÚE, J. H.: Observaciones sobre el clima de Lima. 


\section{LAS TOPOGRAFÍAS MÉDICAS: REVISIÓN Y CRONOLOGÍA}

\section{ORIGEN}

El verdadero origen de las T.M. hay que situarlo en el contexto de la Medicina de la Ilustración. Una serie de circunstancias y de acontecimientos políticos y científicos, situados en diferentes niveles de la realidad social fueron confluyendo, secuencialmente, hasta llegar a dotar a este tipo de estudios con su inequívoco y definitivo perfil «ilustrado». Se han señalado varios de estos acontecimientos.

Sin entrar a valorar en estos momentos la existencia de un más que probable influjo mimético que hubieran tenido en nuestro país las T.M. realizadas por los ingleses y por los franceses, -el «signo de los tiempos»-, hay que destacar, en primer lugar, como antecedente inmediato de las T.M. a la Teoría de las Constituciones de Th. Sydenham. Esta teoría, que restaura el viejo concepto hipocrático de «constitución epidémica» (katástasis) es reinterpretado ahora como el «aspecto meteorológico del año» ${ }^{12}$ y hace del medio ambiente (aire, clima, suelo) el factor determinante de las enfermedades agudas, especialmente de las llamadas por el autor inglés enfermedades epidémicas y estacionales. El estudio de tales constituciones va a ser una constante hasta bien entrado el siglo XIX.

Mas para el médico ilustrado esta mirada hacia el mundo físico exterior para escrutar las alteraciones secretas de la atmósfera y de las entrañas de la tierra, resulta insuficiente. Se están observando también los efectos de la primera industrialización y los cambios sociales que se van produciendo. Esa mirada al exterior, debe pues ser complementada con otra dirigida al espacio social. Como dice Foucault, en la concepción racionalista del universo, típica de la Ilustración, lo fundamental para el médico era «reconocer una señal, situar el síntoma en una enfermedad, la enfermedad en un conjunto específico y situar éste en el interior de un plano general del mundo patológico « $^{13}$. Así pues, era necesario situar al cuerpo humano, a la enfermedad y al individuo en un determinado espacio físico y social (espacios útiles y organizados), de modo que, además de las variables climáticas, de la naturaleza de los suelos y del temperamento individual era necesario contemplar también el aspecto social de las enfermedades (condiciones de trabajo, alimentación, vivienda, etc.) ${ }^{14}$.

12 Laín Entralgo, P y Albarracín Teulón, A.: Sydenham. CSIC. Col. Clásicos de la Medicina, $\mathrm{N}^{\circ}$ 23. Madrid, 1.961. Págs. 46 y sgts.

13 Foucault, M. El nacimiento de la clínica. Edit. Siglo XXI México 1.966, pág. 53.

14 Es lo que hace J.P. Frank en su obra La miseria del pueblo, madre de enfermedades de 1.790. En 1.794, la Convención francesa acordó la dotación de una cátedra de Higiene Pública para atender las necesidades sanitarias del individuo «en tanto que miembro de la sociedad».

Para la constitución de la Medicina Social en España, puede verse, con este mismo título, el trabajo de introducción y recopilaciòn de RODRíGUEZ OCAÑA, E., de la Colección «Clásicos Españoles de la Salud Pública». No 30. Edit. Publicaciones del Ministerio de Sanidad y Consumo. Madrid, 1.987 y la selección de LESKY, E.: Medicina Social. Estudios y testimonios históricos, de la misma colección. Madrid, 1.984 . 
Otro aspecto esencial a considerar en cuanto al origen de las T.M. españolas viene representado por la nueva forma de afrontar la lucha contra las epidemias

La eficacia de las nuevas medidas sanitarias propuestas por el gobierno de Felipe $\mathrm{V}$ para luchar contra la terrible amenaza que representaba la peste de Marsella de 1720, es un ejemplo paradigmático de la nueva política sanitaria. A diferencia del pasado en el que se afrontaba la lucha contra las epidemias de un modo descoordinado, mediante la improvisación, el éxodo personal o colectivo y la apelación a los recursos asistenciales y expiatorios de la Iglesia, se alzaba ahora, frente al «último gran zarpazo de la peste negra sobre Europa ${ }^{15}$ un nuevo sistema sanitario, público, estable, centralizado, laico y burocrático. Enseguida se constituyó una Junta de Sanidad del Reino — desgajada del Consejo de Castilla—y se cortó toda comunicación marítima y comercial con Francia. Nuestro país consiguió llegar a verse libre de la peste.

Este notable éxito serviría posteriormente como modelo a seguir para todos los lugares del Reino en caso de necesidad. De aquí también la gran importancia que cobraría la recién creada Academia de Medicina, — tutelada por el rey desde 1734como impulsora y receptora de toda clase de informes y noticias médicas llegadas desde todos los lugares, incluyendo, naturalmente los lugares de estacionamientos militares.

Una tercera fuente para las T. M. surge del rasgo más característico de la Medicina de la Ilustración: el llamado «naturalismo terapéutico». A diferencia de la complejidad y artificiosidad del arsenal terapéutico de la época barroca — que podría estar simbolizado por las famosas triacas - el naturalismo terapéutico de la Ilustración «refleja el gusto de la época y su peculiar estimación de la naturaleza» ${ }^{16}$. Está muy generalizada, en efecto, la confianza en la fuerza curativa de la naturaleza - el agua, los baños, el ritmo estacional, los lugares saludables, etc.- - en la de sus elementos simples y en su dinámica interna que por entonces se iban descubriendo y desvelando: el oxígeno, el cloro, la electricidad, la vacuna, etc.

La teoría de las Constituciones de Sydenham, la nueva política sanitaria y el naturalismo terapéutico, son los tres grandes rótulos que contribuyeron a diseñar el perfil definitivo de las T. M. en el siglo XVIII. Estas tres cuestiones se entrecruzan también en una obra que puede ser considerada - a mi juicio - como el verdadero punto de arranque de las T.M. españolas.

Nos referimos al Plan General de Efemérides meteorológico-médicas de Francisco Fernández Navarrete, médico de cámara de Felipe $\mathrm{V}^{17}$ propuesto en 1737 a la

15 Peset, M. y PeSet, J.L.: Muerte en España. Edit. Seminarios y Ediciones, S.A. Madrid, 1.972.

16 Laín Entralgo, P.: Historia de la Medicina Moderna y Contemporánea. Edit. CientíficoMédica, $2^{\text {a }}$ edicción. Barcelona,1.963, pág. 319 y sgts

17 Francisco Fernández Navarrete era médico de cámara de Felipe V y profesor de anatomía en la Universidad de Granada. Partidario del «naturalismo terapéutico», es el autor —entre otras obras- de un Tratado sobre la constitución de los tiempos (1.738) y de una Disertación sobre el carácter de los espa- 


\section{LAS TOPOGRAFÍAS MÉDICAS: REVISIÓN Y CRONOLOGÍA}

Real Academia Médico-Matritense e inmediatamente adoptado y tutelado por ella; la publicación de dichas Efemérides corrió a su cargo entre 1737 y 1746.

El plan de Fernández Navarrete, factible ya, gracias a la presencia de instrumentos como el barómetro y el termómetro, fué, en su origen, una respuesta a la llamada general que había hecho en 1725 la Royal Society de Londres para que se verificasen observaciones meteorológicas en toda Europa. Como hemos dicho, este plan fué aceptado por la Academia la cuál, sin embargo, quiso ir aún más lejos:

«Pero siendo tan estrecha la unión entre la medicina de un país y la historia natural de él, bien reflexionada e ilustrada con la disciplina físico-matemática...la Academia...» (se hace cargo) «del proyecto de historia natural y médica de España, disponiendo su ejecución con distribución tan armoniosa y comprensiva como se verá a su tiempo» ${ }^{18}$.

El plan de Efemérides iniciado por Fernández Navarrete —que también está en el origen de los observatorios españoles- fué continuado luego por Argandoña pero perdió su impulso a mediados del siglo. Sus ideas fueron recogidas algo más tarde por Campomanes en 1784 para el mejoramiento agrícola y complementadas luego con los planes observacionales impulsados por el Dr. Salvá por intermedio de la Academia de Medicina de Barcelona, y por las observaciones meteorológicas de Sanchez Buitrago en Cádiz, Salanoba, Guillemin y Casal en Madrid y Bals y Cardona en Mahón. Poco después, en 1792, presentó Antonio Valdés a Floridablanca el proyecto de observaciones que había elaborado Malaspina para todo el vasto imperio colonial, el cual debería centralizarse ahora, no en la Academia de Medicina, sino en la de Guardiamarinas de Cádiz, «mientras no se haya formado la de ciencias de esta Corte» ${ }^{19}$.

Todos estos planes observacionales se proyectaron para ser útiles «a la agricultura, a la higiene pública, a sus topografías médicas, a la estadística y a todas las ciencias de gobierno y recta y bien entendida administración ${ }^{20}$.

\footnotetext{
ñoles. La obra a la que nos referimos lleva por título Efemérides barometricomedicas matritenses, para el más puntual y exacto cálculo de las observaciones que han de ilustrar la historia natural y médica de España (Madrid, 1.737).

18 Son palabras del presidente Cervi recogidas por Manuel Rico Sinobas, médico y profesor de Física de Universidad Central a mediados del siglo XIX, en los «Estudios meteorológicos y topografías médicas en España en el siglo XVIII» publicados en El Siglo Médico en los números 215 al 218 ( Febrero-Marzo de 1.858).

19 Carta de Antonio Valdés al conde de Floridablanca, transmitiéndole las ideas de Malaspina,. Carta reproducida por RICO SINOBAS, en o.c., pág. 6.

20 Rico SinOBAS, M. o.c. pág. 15.
} 


\section{TOPOGRAFIAS MEDICAS DEL SIGLO XVIII}

En la lista de T.M. citadas por Hernández Morejón se incluían los trabajos médico-topográficos de Casal, Piquer y Unanúe sobre Asturias, Valencia y Lima, respectivamente. Estos autores, como es sabido, entran de lleno en la Medicina de la Ilustración española y por ello, desde mi perspectiva, no deben ser considerados como precursores sino como constituyentes, y sus trabajos, como trabajos fundadores de estos estudios. Por otra parte son figuras muy conocidas, especialmente los dos primeros, de modo que no precisan ahora de más comentarios.

Pero como es natural, no son éstas las únicas T.M. que se realizaron durante el siglo XVIII. De forma muy destacada hay que incluir la obra de A. Pérez de Escobar ${ }^{21}$ publicada en Madrid en 1788 titulada Medicina Patria o Elementos de Medicina Práctica de Madrid, que puede servir de aparato a la Historia Natural Médica de España. Esta primera T.M. de Madrid bien merecería los honores de ser reeditada.

En el fondo documental de manuscritos del siglo XVIII de la Real Academia Nacional de Medicina ${ }^{22}$, se pueden encontrar entre 1.737 y 1.800 -fecha convencionalmente admitida como la del fin de la Medicina de la Ilustración - no menos de una treintena de obras relacionadas con estudios médico-topográficos: Topografías médicas propiamente dichas ${ }^{23}$, estudios de «constituciones epidémicas» de diversas localidades y noticias sobre fiebres endémicas ${ }^{24}$ llegadas a la Academia desde todas las regiones. Son de destacar así mismo, los primeros informes que se hacen sobre las condiciones de trabajo en relación con la salud: minas de Almadén, fábricas de jabones, cultivos de arroz, etc. ${ }^{25}$.

Las Academias médicas continuaron reafirmando en sus estatutos la necesidad de realizar estudios topográficos; los estatutos renovados de la de Madrid (1.796) y los nuevos de la de Barcelona (1.786) así lo establecían explícitamente. De este último

\footnotetext{
21 Antonio Pérez de Escobar fue médico examinador del Protomedicato y primer médico del convento de la Encarnación.

22 Este Catálogo (Madrid, 1.996) ha sido elaborado por L. Maldonado y S. Pinar, bajo la coordinación de A. Albarracín.

23 Topografía Médica de Colmenar de Oreja, por Fernando Yebra. 1796.

24 Puede servir de ejemplo la memoria de Luzuriaga, el famoso «médico ilustrado»: Memoria sobre la epidemia que se padeció en la villa de Lequeitio el año 1.769. Escrita por José de Luzuriaga y dedicada a la Real Sociedad Bascongada de los Amigos del País. 1.769.

25 * Almadén (30-XII-1.792). Nota de José Parés y Francés acerca de una disertación del médico de las minas de azogue.

* Sin fecha. Cavanilles. Observaciones sobre el cultivo de arroz en el reino de Valencia y su influencia en la salud pública. Peset y Vidal dice que esta obra es de 1.795.

* Dictamen de José Martínez de San Martín y Tomás García Suelto Sobre la salubridad de la fábrica de Jabón radicada en Granada. 1805.
} 


\section{LAS TOPOGRAFÍAS MÉDICAS: REVISIÓN Y CRONOLOGÍA}

punto procede la brillante tradición catalana de estudios médico-topográficos, continuada posteriormente por numerosas generaciones de médicos ${ }^{26}$.

\section{DESARROLLO HISTÓRICO}

\section{I. Época prebacteriana}

Sin contar los trabajos ya mencionados, para el período comprendido entre 1.800 y 1.970 , he registrado un total de 307 TM que se recogen en el anexo de este trabajo en forma de anuario. Veamos ahora cual ha sido, a grandes rasgos, la evolución histórica de este «corpus topográfico».

Por lo que se refiere al despliegue del higienismo, a la evolución de las ideas patogénicas y a las T.M., lo primero que se observa en el panorama general de estos ciento sesenta años, es que éste se encuentra dividido por una gran cresta divisoria situada justamente en su mitad, y que delimita, claramente, dos grandes épocas en la historia de la medicina.

Esta gran línea divisoria correspode a la emergencia y consolidación del llamado «modelo bacteriológico de enfermedad»; este modelo se constituyó como una clave que abrió una nueva época en la historia de la medicina. El escenario en el que se desenvolvían las T.M. se dividió también en dos mitades: una anterior a la irrupción del paradigma microbiano —el término «microbio» aparece en 1878- que podría ser denominado, no sin algunas reservas, como «período miasmático», y otro posterior o post-bacteriano.

El modelo bacteriológico de enfermedad puede darse por definitivamente consolidado, como es conocido, en la octava década del siglo XIX. En nuestro país podríamos situar la línea fronteriza de estas dos grandes épocas en torno al eje del bienio 1.885-1.886, fechas de la última gran pandemia del cólera, de las polémicas con el Dr. Ferrán acerca de su vacuna anticolérica, y también, precisamente, el bienio en el que se produce el mayor número de T.M. de toda la historia, catorce, según mi registro, cifra equivalente al conjunto de la producción de las tres primeras décadas del siglo.

Tenemos pues, una primera época, pre-bacteriana, que abarca desde 1.800 hasta 1.885. Esta época está dominada, no sin numerosas excepciones, por una concepción de las enfermedades agudas y epidémicas, en gran parte heredera de la teoría de las constituciones, que podría encuadrarse dentro del «modelo miasmático de enfermedad». Este modelo, que vendría a representar en el siglo XIX un papel parecido al

26 De este tiempo es la Topografía médica de la comarca de Alcira, escrita por su médico Francisco Llansol (1.750-1.805), como respuesta al plan impulsado desde la Academia de Medicina de Barcelona por F. Salvá y F. Sanponts. 
que hoy atribuímos a la contaminación ambiental, es en realidad una teoría focal o «topográfica» de la enfermedad: desde unos focos «pestíferos» (pantanos, aguas putrefactas, vertederos, depósitos de materias orgánicas en descomposición, etc.) se producirían exhalaciones o gases patógenos que al ser dispersados por los vientos, serían causas de enfermedades. Es un modelo acorde con las ideas fisiopatológicas propias del período de la Medicina del Romanticismo.

Con todo, esta época no es homogénea. Dentro de ella, en nuestro país, pueden delimitarse dos períodos con características diferenciadas.

El primero de ellos viene acotado por las fechas de la primera gran epidemia de fiebre amarilla -1.800- y de la primera gran pandemia de cólera morbo asiático 1.834- enfermedad difundida extraordinariamente con las expediciones militares de la primera guerra carlista. Este período, 1.800-1.834, políticamente tan azaroso, estuvo dominado por la guerra, el exilio liberal, el absolutismo, el subdesarrollo económico y el retroceso científico y cultural. Implicó la quiebra del ideal ilustrado y se objetivó como una «ilusión quebrada» ${ }^{27}$. Sanitariamente, este período estuvo ocupado por la fiebre amarilla, las malarias patrias o endémicas, y por las polémicas científicas - con un indudable trasfondo político — entre los partidarios del contagio de las enfermedades, y por tanto, del aislamiento de los enfermos y de la interrupción de los intercambios personales y comerciales, y los anticontagionistas, a quienes estas medidas les parecían excesivamente restrictivas ${ }^{28}$.

Las escasas T.M. que se produjeron durante este período ${ }^{29}$ no son ajenas a estas polémicas, pero por regla general, siguieron inercialmente el modelo perfilado en la Ilustración e inspirado en la teoría de las constituciones epidémicas. Son muy notables, entre ellas, las T.M. de los por entonces dos jóvenes médicos rurales que luego llegarían a ser figuras eminentes de la medicina española: las T.M. de Reus (1.820) y de Cebreros (1.830) de Jaime Ardevol ${ }^{30}$ y de Anastasio Chinchilla ${ }^{31}$ respectivamente.

27 Este es el título de un libro esclarecedor sobre la crisis de la política científica de aquellos años. «La Ilusión quebrada». Botánica, Sanidad y política científica en la España Ilustrada. De F. J. Puerto Edit. Serbal- CSIC. Madrid, 1.988.

28 Puede verse en detalle esta polémica en PESET, M.y PeSET, J.L. o.c. capítulos X y XI.

29 Sobre la escasa producción científica de la medicina española durante el primer tercio del siglo XIX, pueden servir estas ilustrativas palabras de F. Méndez Alvaro:

«Suele acusárseles (a los médicos españoles) de inactivos porque no escriben, porque no publican sus observaciones o pensamientos porque no leen... ¿quién trabaja, quién estudia, quién escribe, cuando carece hasta de lo necesario para vivir, cuando absorbe toda su atención la necesidad de buscar pan con que alimentar a sus hijos»

«Estado actual de la Medicina en España». Semana de Medicina, № 1. 7 de Enero de 1.841.

Hay que tener en cuenta que la reforma de 1.830 de los Estatutos de la Real Academia de Medicina, tradicional impulsora de estos estudios, implicó la pérdida de su rango nacional, quedando reducida, hasta 1.861 , a un ámbito meramente regional.

30 ARDEVOL, J. Ensayo sobre la topografía y estadística de la villa de Reus en Cataluña. Imp. Espinosa. Madrid, 1.820. Aunque en esta fecha de publicación el autor era ya de edad madura, en realidad su 


\section{LAS TOPOGRAFÍAS MÉDICAS: REVISIÓN Y CRONOLOGÍA}

El segundo período (1.835-1.885) tiene por telón de fondo el proceso de institucionalización de la Sanidad Pública española, en el contexto de la construcción del nuevo Estado Liberal, y la lucha contra las grandes oleadas epidémicas del cólera ${ }^{32}$.

Para las T.M. este período tiene una especial relevancia. A lo largo de los años las T. M. fueron madurando sus conceptos y modernizando sus posiciones - algunas de ellas habían recaído en adulaciones más propias de las guías de forasteros que de trabajos científicos - hasta lograr una sólida estructura interna. En esta labor hay que destacar, en primer lugar, la obra topografica de J.B. Peset y Vidal, médico del Hospital General de Valencia y director de su Manicomio, que había tenido una larga experiencia como médico rural. Fruto de esta experiencia fueron sus dos estudios médicos sobre Motilla del Palancar (1.849) y Alcántara (1.860) ${ }^{33}$. Pero la obra culminante de este periodo es, sin duda, su estudio sobre Valencia (1.878) trabajo que le llevó varios años y que fué considerada como el modelo a seguir para la confección de las T.M. del futuro ${ }^{34}$.

Otros importantes estudios de este período son los de Martínez Montes (1.852), citado elogiosamente por Peset y Vidal, los de Weyler sobre Mallorca (1.854), los de Manero sobre Alicante (1.882), que sigue la pauta marcada por el citado Dr, Peset, y los de $\mathrm{Ph}$. Hauser sobre Sevilla (1.884), iniciando así este autor una brillante carrera como higienista.

Durante estos años vuelve a dedicarse cierta atención a los territorios que quedaron como restos del antiguo imperio colonial: T.M. de La Habana (1.851 y 1.857), Cuba (1.855), Filipinas (1.857) y Norte de Marruecos (1.860), de Sánchez Rodríguez, Dupierris, Codorníu y Weyler, respectivamente.

T.M., trata, básicamente, de la calentura mucosa que se asentó en Reus en plena guerra de la Independencia y que tuvo ocasión de vivir. El autor (1.775-1.835), doctorado en Montpellier, director del lazareto de Gibraltar, escribió también diversas memorias sobre la fiebre amarilla.

31 Chinchilla,: A. Disertación Histórico-Físico-Médica de la villa de Cebreros. 1830. Manuscrito (RANM). En esta T.M. sigue el autor (1.801-1.867), que luego sería importantísimo historiador de la medicina española, la descripción meteorológica del año y la distribución de las enfermedades, al modo de Sydenham, describiendo nueve «constituciones» a lo largo de ese año.

32 Sin contar con algunos breves repuntes, fueron cuatro las grandes ondas epidémicas del cólera que se abatieron sobre nuestro país: $1.833-1.835 ; 1.853-1.856 ; 1.865$ y $1.884-1.885$.

33 Juan Bautista Peset y Vidal (1.821-1.885):

* Geografía Médica de Motilla del Palancar. 1.849.

* Topografía Médica de la Villa de Alcántara.1.860.

34 PeSeT Y VIDAL, J.B. Topografía Médica de Valencia y su zona. Imp. Ferrer,Valencia.1878. Obra premiada por la Academia de Medicina en 1.870, puede ser considerada como la más importante de este período. Distribuye sus secciones de este modo: Exposición topográfica, Condiciones individuales y sociales, («es incuestionable — dice el autor- la influencia que sobre la salud del hombre ejerce su posición social»), Higiene Pública, Etiología, Distribución de enfermedades, Demografía. 


\section{Epoca post-bacteriana}

Puede acordarse la fecha de 1.885 como punto de inflexión para la consolidación en nuestro país del modelo positivista y microbiano de enfermedad. Ciertamente, la irrupción de este modelo llevó consigo una revolución en el desarrollo de las ideas etiopatológicas, abrió todo un mundo nuevo a las higiénicas y sanitarias y permitió la creación de una nueva nosología: se hablaría ya de brucelosis, salmonelosis, estreptococias, etc. En España tuvieron que reformarse las cátedras de Higiene en 1.904 — sin mucha rapidez de reflejos - para adaptarse a las nuevas realidades científicas.

Algunos autores han creído ver aquí, con la emergencia de este paradigma, el comienzo de la decadencia de los estudios médico-topográficos. Según ello, el saber positivo - bacteriológico - al descubrir la causa cierta del origen de las enfermedades contagiosas, al derrumbar las tradicionales doctrinas miasmáticas y telúricas, arrastraría en su caída a las T.M., las cuales persistirían luego en su decadencia aferrándose de una manera reaccionaria a modelos científicos ya caducos y pasados. El éxito del enfoque etio-patológico «echará por tierra el marco teórico de las topografías» ${ }^{35}$ Esta tesis implica o supone la existencia de una identificación esencialista entre el método tradicional de las T.M. y una determinada doctrina etiopatogénica y fisiopatológica. Pero las T.M. no son portadoras de un determinado y concreto modelo de enfermedad, sino que proponen un método multidimensional para abordarlas y un enfoque dialéctico y complejo para contextualizarlas.

Como señala Laín Entralgo ${ }^{36}$, el nuevo paradigma bacteriano — cuyo principal teorizador fué Klebs-, se asentaba en tres pilares. Uno: la causa de las enfermedades es un agente microbiano externo al organismo humano y reconocible objetivamente. Dos: la enfermedad es el resultado de la lucha que sostienen los microbios invasores y las células del organismo. Y tres: el modo de enfermar depende de cual sea el agente patógeno causal. Dicho sea de paso y, como suele decirse, salvando las distancias, si cambiamos el nombre de bacteria por el de gen, y el de infección por transmisión genética, este esquema parece reactualizarse en nuestros días, en los que se puede percibir la existencia de un trasfondo conceptual algo simplista, que recuerda al de hace un siglo.

Pues bien, a mi juicio, lo que ocurre con las T.M. en este período post-bacteriano, no consiste tanto en una supuesta resistencia inercial y reaccionaria ante el nuevo modelo explicativo, sino que, por el contrario, creemos que lo que se produce es una «integración» de la microbiología, en tanto que saber positivo, en su tradicional molde omnicomprensivo ${ }^{37}$. En mi entender, tal integración contribuyó a revitalizar el

\footnotetext{
35 L. URTEAGA, en o.c.

36 Laín Entralgo, P. o.c. Pág. 587.

37 HAUSE, Ph. (1903), Conveniencia del estudio de la Topografía Médica para formar la Geografía Médica Tip. Sucesores de Rivadeneira. Madrid.
} 


\section{LAS TOPOGRAFÍAS MÉDICAS: REVISIÓN Y CRONOLOGÍA}

interés por los estudios médico-topográficos en el gozne de los siglos últimos. Pueden citarse algunos hechos. El IX Congreso Internacional de Higiene y Demografía celebrado en Madrid en abril de 1.898, días antes del desastre colonial, reservó una sección para las T.M; y allí se presentaron, entre otros trabajos, las T.M. de Almería, Logroño, Coca, Tarancón, Jaca, Saldaña y Mogente. En 1.904 se lanzó un proyecto de ambición nacional para realizar las 8.000 topografías de los pueblos de España, esta vez con una clara intencionalidad regeneracionista; las Academias de Madrid y Barcelona incrementaron su interés por las T.M., y en fin, en 1.906 la Academia de Zaragoza instituyó el legado del Dr. Gari para premiar a la mejor memoria sobre «El clima y la topografía como elementos etiológicos en la evolución de las enfermedades infecciosas». Así pues, el hecho bacteriano sustituyó, naturalmente, a la exhalación miasmática, pero la perspectiva holística de las TM continuó vigente. Como indicaré más adelante, hay que situar las razones de la decadencia y desaparición de las TM en otros contextos.

Además, el simplista esquema diseñado por Klebs pronto entraría en crisis, al tener que confrontar hechos tan complejos como el de la inmunidad, y explicar por qué muchos individuos infectados no sufrían la enfermedad, o como el de la morbilidad, una morbilidad bien diferente según cuales fueran las condiciones de vida y la posición de los individuos dentro de la escala económica y social.

En este sentido, la obra de higienistas tan importantes como Iglesias Díaz y Ph. Hauser, subrayan con frecuencia la necesidad de continuar cultivando los estudios médico-topográficos, incluyendo los nuevos avances de las ciencias de la salud, sin descuidar el análisis de los determinantes sociales de las enfermedades. Las T.M. de la época dedicarán bastante espacio a las patologías sociales derivadas del pauperismo, al alcoholismo, a la tuberculosis y a las enfermedades de transmisión sexual, a la sífilis, especialmente.

También aquí, en esta época post-bacteriana, pueden delimitarse dos períodos diferentes, claramente definidos. El primero de ellos duraría desde la fecha indicada de 1.885 hasta 1.936. La guerra civil significó un brusco corte en nuestra historia que afectó a todas las actividades y ramas del conocimiento y por lo tanto, también a las T.M.

Durante cuarenta años, entre 1.885 y 1936, viven las topografías médicas su período más maduro y fecundo. Esto es incuestionable, al menos desde el punto de vista cuantitativo ${ }^{38}$; fecundidad a la que no fue ajena, como hemos dicho, el nuevo impulso aportado por las fundaciones académicas.

«...las conmociones político-sociales que sufrió la sociedad europea en el siglo XIX al mismo tiempo que han transformado las condiciones fundamentales de la existencia, han debilitado su resistencia vital, haciéndola apta á servir de medio de cultivo favorable á los numerosos microorganismos patógenos» (pág.7).

Y sigue Hauser refiriéndose después a fenómenos como el hacinamiento de las ciudades y al «mefitismo» urbano.

38 Un total de 186 T.M. he registrado en este período, entre manuscritos y topografías publicadas. 
En el panorama general de las T.M. de este período destaca en primer lugar la obra de Ph. Hauser, que cumple en él un papel parecido al de Peset y Vidal en el anterior. Su obra Madrid desde el punto de vista médico-social, de 1903, marcó un nuevo hito en la historia de las topografías médicas españolas. En segundo lugar hay que señalar el fuerte impulso dado a estos estudios por la Fundación «García Roel» ${ }^{39}$ de la Real Academia Nacional de Medicina. Al amparo de esta fundación, hasta el comienzo de la guerra civil se realizaron una veintena de T.M. de localidades de la provincia de Madrid, y otras tantas de la de Asturias.

Por citar algunas T.M. de este período tan fecundo, destacaremos, además de la ya citada, las T.M. de Pérez Giménez sobre Cabeza del Buey y la comarca de La Serena (1.888), la de la Asociación Médica de Navalcarnero (1.896), y los trabajos de Hernández Briz, Joaquín Truixans, Fermín Yriagaray, Vilar y Ferrán, Villalain, Jové y Canella, Alvarez Sierra y un largo etcétera.

El segundo período de esta época, apenas si se extiende durante dos décadas. La producciòn de T.M. en los años cuarenta y cincuenta descendió notablemente, hasta convertir su presencia en puramente testimonial. Los estímulos provenientes de las fundaciones académicas se fueron debilitando hasta llegar a desaparecer. No obstante, al abrigo de los Premios Roel — de cada vez más incierta convocatoria- se realizaron algunas notables T.M.: las de El Alamo, del paremiólogo Castillo de Lucas (1.941), Aranjuez (1.948) y Ciempozuelos (1.955) pueden servir de ejemplo

En este tiempo se produjeron también otro tipo de T.M. de alcance más ambicioso. Perseguían además unos objetivos de reconstrucción histórica; trataban de rehacer la historia de las localidades tras la destrucción y pérdida, por causa de la guerra civil,de sus archivos y fondos documentales ${ }^{40}$.

\section{CONCLUSIÓN}

Las T.M. nacieron durante la Ilustración, tuvieron su época de madurez en el borde de los siglos XIX y XX y desaparecieron en los años sesenta de este siglo. Asistamos ahora a este proceso de extinción.

Las T.M. desaparecieron en cuanto tales, ciertamente, pero en modo alguno se debilitó la corriente de pensamiento que ellas albergaban y a la cual hemos aludido repetidamente. Por el contrario, la pujanza de esta línea de pensamiento — simbolizada

39 Faustino García Roel (1.819-1.895), médico asturiano, decano honorario de la Beneficencia Provincial de Oviedo, legó fondos a la Academia Nacional de Medicina para dotar a una Fundación que premiaría las T.M. de un partido judicial o de un término municipal, de Asturias y de Madrid, alternativamente, en una primera fase, con posibilidad de extenderlo luego a toda la geografía nacional.

40 CAsco Arias, J. Geobiografía e Historia de Quintana de la Serena. Edit. Prensa Española, Madrid, 1.961 . 


\section{LAS TOPOGRAFÍAS MÉDICAS: REVISIÓN Y CRONOLOGÍA}

ahora en el concepto de salud entendido como bienestar físico, mental y social- desbordó sus límites hasta llegar a convertirlas en innecesarias.

En realidad, las T.M. fueron desapareciendo, básicamente, porque sus contenidos iban siéndole arrebatados por el desarrollo acelerado de las ciencias naturales y por la implantación tras la segunda guerra mundial de los sistemas sanitarios públicos de amplias coberturas.

Por una parte, los geógrafos fueron ocupándose, cada vez más, de las relaciones entre el medio físico y los seres humanos. Desde finales de los años veinte de este siglo, la «Geografía Medica» fue cultivándose dentro de la Geografía Humana, hasta llegar a constituir una entidad específica. Esta disciplina, propia ya de geógrafos, aunque abierta a aportaciones multidisciplinares, recibió un fuerte impulso, por necesidades bélicas, durante la segunda guerra mundial. La «Geografía Médica» tuvo su primer reconocimiento oficial en 1949 en el Congreso Internacional de Geografía de Lisboa. A partir de aquí, los estudios bio-geográficos — que siempre reconocieron el papel histórico de las T.M.- experimentaron un rápido crecimiento. En la actualidad incluyen también en sus análisis referencias a situaciones socioeconómicas y al equipamiento sanitario de los territorios, por lo que se habla cada vez más de «Geografía de la Salud» ${ }^{41}$.

En segundo lugar, con el auge de los sistemas sanitarios públicos y con el desarrollo de la Seguridad Social, y debido a sus necesidades intrínsecas (necesidades de evaluación, de control de los sistemas, de distribución de recursos, etc. ), el papel de las T. M. fue relegándose como un anacronismo más propio de las formas organizativas sanitarias del pasado. Pero este papel, es similar al que ahora pudieran representar los llamados «Estudios Socio-Sanitarios» de las zonas, áreas o distritos, o cualesquiera otras formas de espacios sociales que delimitan las modernas territorializaciones sanitarias.

El tradicional enfoque integrador de los procesos de salud y de enfermedad que ellas representaban, su modelo holístico y su mirada omnicompresiva, persisten también en nuestros días impregnando con su manera de pensar a los llamados modelos comunitarios de atención sanitaria. El estudio de estas eventuales conexiones bien pudiera merecer una serie de trabajos. Baste ahora con subrayar el hecho de que estos modelos comunitarios, donde han cobrado más pujanza sea precisamente en los campos de la Medicina Familiar y en los de la Salud Mental

A la hora de evaluar el papel histórico de las T.M., es preciso reconocer también sus aportaciones a otras áreas del conocimiento. Dentro del enorme caudal de datos que contienen - aún insuficientemente explotados- destacan los relativos a la antropología cultural (costumbres, creencias, rituales, medicinas populares, etc.), a la historia de las mentalidades y a la psicologia: desde el principio las T.M. han cultiva-

41 Olivera Poll, A. Nuevos planteamientos de la Geografía Médica. Univ. Autónoma de Madrid. 


\section{JUAN CASCO SOLÍS}

do la psicología comparada — «intra-cultural», podría decirse—, acaso por la persistencia de viejos reflejos hipocráticos renovados por la savia de la Ilustración ${ }^{42}$

Termino este trabajo con una cita muy expresiva de P.F. Monlau,de 1.847:

«Todas las poblaciones han de tener su topografía. El manuscrito que las contenga debe ser custodiado en los archivos de la Casa Municipal como un «libro de familia». Este libro será consultado con mucho fruto para saber lo que ha sido la población, lo que es y lo que puede ser. Se agregarán en forma de apéndices a dicho libro los resultados de cada año. Estos anales locales, bien redactados, serán la joya más preciosa de la población. Bueno fuera que las topogrfías se imprimieran para la común instrucción e imperdible recuerdo» ${ }^{43}$

42 Hay que tener en cuenta que uno de los partidarios de este enfoque fue Montesquieu, el cual dedicó toda la $3^{\text {a }}$ Parte del Espíritu de las Leyes al estudio de las relaciones entre las leyes y la naturaleza del clima y del suelo.

43 Monlau, P.F. Elementos de Higiene Pública, Madrid, 1.847. 


\title{
LAS TOPOGRAFÍAS MÉDICAS: REVISIÓN Y CRONOLOGÍA
}

\begin{abstract}
ANEXO
Se incluyen en este anexo las TM recogidas de muy diversas fuentes y ordenadas cronológicamente a fin de facilitar la percepción de los períodos más fecundos y de los años más estériles en cuanto a la producción de las mismas. Sobre la base de las 224 que ya recogía L. Urteaga, se añaden otras hasta rebasar ampliamente la cifra de trescientas. La mayor parte de ellas se encuentran entre los fondos bibliográficos de la Real Academia Nacional de Medicina (RANM) y de la de Barcelona.(RAMB) Pero no todas. Otras se encuentran dispersas por un buen número de publicaciones médicas —algunas, ciertamente, de difícil acceso- pertenecientes a distintas épocas. En otras, muy pocas, por fortuna, no ha podido datarse la fecha exacta de elaboración o de publicación. Esta lista no pretende ser exhaustiva
\end{abstract}

\section{T.M. ANTERIORES AL SIGLO XVIII}

Benjamín de Tudela. Se le atribuye (Peset y Vidal) una Topografía de Zaragoza. Siglo XII. Publicada en 1.575.

Juan de Aviñón: Sevillana Medicina. 1.393. Impresa en 1.547.

Diego Cisneros: Sitio, naturaleza y propiedades de la ciudad de México. 1.618.

Nicolás Francisco de San Juan y Domingo. Se le atribuye una Topografía de Aragón. 1.686.

Gaspar Casal: Historia Natural y Médica del Principado de Asturias. Madrid, 1.762.

Andrés Piquer. Hernández Morejón le atribuye una TM de Valencia. Peset y Vidal, sin embargo, no la encuentra entre el registro general de sus obras.

José Hipólito Unanue: Observaciones sobre el clima de Lima. (Publicada en Madrid).

Antonio Pérez de Escobar: Medicina Patria o Elementos de Medicina práctica de Madrid. Madrid, 1.788.

Fernando Yebra: Topografía Médica de Colmenar de Oreja. Manuscrito. (RANM) 1.796.

Francisco Llansol: Topografía Médica de Alcira y de los Riberos del Xúcar. Manuscrito (RAMB) 1.797.

\section{T.M. DEL SIGLO XIX}

1.802 .

GELABERT Y RIERA, F.: Essai sur la topographie mèdicale de GIRONA, presenté a l'ecole de Médecine de Montpellier le 29 de ventôse, an X de la Republique Francaise. Imp. Concorde. An X.

1.805

Garcia Suelto Tomás.: Topografía Medica de MADrid. En Variedades de Ciencia, Literatura y Artes. Año II (1.805) Tomo I, págs 3-20.

1.806

HeRnANDEZ (¿Morejón?). Topografía del Hospital Militar de Mahón. Manuscrito (RAMB). 


\section{JUAN CASCO SOLÍS}

1.808

GonZALEZ: Descripción topográfica de CÁDIZ. Manuscrito (RAMB).

1.816

RABASSA FONTSERE J.: Estudio topográfico de LERIDA. Manuscrito (RAMB).

1.817

Mochales, Agapito: Disertación topográfica del valle de SOLANS DE CABRAS situado en la provincia de Cuenca.

1.820

ARDEVOL Jayme: Ensayo sobre la Topografía y Estadística de la Villa de REUS. Imp. Espinosa. Madrid.

1.821

ANONIMO: Observaciones físico-médicas de MADRID y sus alrededores. Décadas médicoquirúrgicas. Tomo I-III

1.822

Gil Albeniz.: Topografía Médica de CASCANTE. Pamplona.

GONZALEZ: Topografía de MALAGA y su provincia. Manuscrito (RAMB).

1.826

ARRUTI, Francisco.: Descripción topográfico-médica de la ciudad de SAN SEBASTIAN. Manuscrito.

1.830

CHINCHILla, Anastasio.: Disertación histórico-físico-médica de la villa de CEBREROS. Manuscrito (RANM).

1.831

ANONIMO.: Descripción topográfico-médica de la villa de UTRERA. Manuscrito.

ORTI CRIADO, Vicente.: Tratado de topografía Médica de la villa de MARMOLEJO. Manuscrito.

VIDAl y PEREZ, Bernardo. Descripción topográfico-médica de la villa de ALCALA DE GUADAIRA. Manuscrito.

1.833

SAnChez Larios, P.: Descripción topográfico-médica de la villa de Constantina. Manuscrito.

1.834

MARIN, Francisco. Descripción topográfica de la Plaza de CEUTA. Manuscrito.

1.835

GONZALEZ Y CRESPO, M.J.: Topografía de la villa y baños de TRILLO. Guadalajara.

1.838

Davalos, Manuel.: Disertación sobre la topografía, historia natural y médica de la villa de EL MOLAR. Manuscrito. 


\section{LAS TOPOGRAFÍAS MÉDICAS: REVISIÓN Y CRONOLOGÍA}

1.839

PEREZ, Carlos.: Topografía médica de JAEN. Jaén.

1.841

LOPEZ PosADA, Vicente.: Bosquejo topográfico natural y médico de la provincia de OVIEDO. Manuscrito.

1.848

CASTILlO Y ESPINOSA, J.M. del.: Memoria acerca de las aguas y baños termo-minero-medicinales de ALHAMA DE MURCIA, que comprende la descripción topográfica de dicha villa. Murcia.

1.849

CASElles y COLL, Pedro.: Ensayo topográfico - filosófico- médico, o sea, reseña circunstanciada de la localidad y de los habitantes de la M.L.V. de OLOT. Barcelona.

PeSET Y VIDAL; J.B.: Geografía médica de Motilla DEL PALANCAR. Madrid.

1.850

RoDriguez CARREÑo, Manuel.: Memoria descriptiva de la villa de MALA, sus salinas y baño termal. Imp. Astudillo y Garrido. Granada.

Ruiz De SAlaZAR, Manuel.: Descripción geográfica y topográfica del valle de ToRAnZo, en la provincia de Santander. Baños de Ontaneda y Alceda. Imp. G. Alhambra. Madrid.

1.851

POBLACION FERnANDEZ, Antonio.: Topografía médica y enfermedad reinante de la villa de MEDINA DEL CAMPO. Valladolid.

SANChez RodrigueZ, I.: Descripción del partido y baños de SAN Diego. La Habana.

1.852 .

MARTINEZ y Montes, Vicente. Topografía médica de la ciudad de MALAGA. Imp. Ramón Franquelo. Málaga.

1.854

ANONIMO.: Topografía médica de la ciudad de ZARAGOZA. Manuscrito (RANM).

MEsTRE, Carlos.: Topografía físico-médica y antigüedad de la villa y aguas de PUERTOLLANO. El Heraldo Médico, año III, nº 115-123.

WEYLER Y LAVIÑA, Fernando.: Topografía físico-médica de las ISLAS BALEARES y en particular de la de Mallorca. Imp. Gelabert. Palma de Mallorca.

1.855

PIÑA Y PEÑUELA, Ramón.: Topografía médica de la isla de CUBA. La Habana.

1.856

CASELLAS.: Observaciones topográfico-médicas de OLOT. Manuscrito (RAMB).

1.857

ANONIMo.: Manual descriptivo e histórico de la ciudad de SAN SEBASTIAN, con un apéndice sobre los baños de mar. Imp. Ramón Baroja.. San Sebastián. 


\section{JUAN CASCO SOLÍS}

Codorniu y Nieto, A.: Topografía médica de las ISLAS Filipinas. Imp. Alejandro G. Fuentenebro. Madrid.

DUPIERRIS, Marcial.: Memoria sobre la topografía de LA HABANA y sus alrededores, y sobre el estudio físico y moral de las colonias asiáticas. La Habana.

1.859

ANONIMO.: Topografía médico-botánica de VALLADOLID. Manuscrito (RANM).

RODRIGUEZ CARREÑO, Manuel.: Descripción geográfica y topográfica de la villa de DALIAS. Imp..Antonio Cordero. Almería.

VILANOVA Y PIERA, Juan.: Memoria geognóstico-agrícola sobre la provincia de CASTELLON Imp. Eusebio Aguado. Madrid.

1.860

LeON LuQue, P.; De Haro, J.;Viñas, S.; Blasco, P.; Custodio, A.: Topografía y estadística médica de la parroquia de SAn LoRenzo. La España Médica. Tomo V. págs. 274-81; 289-96; 308-13;322-27, y 340-43.

PESET Y VidAL, J.B. Geografía (o Topografía) médica de AlCANTARA.

WEYLER Y LAVIÑA, Fernando.: Apuntes topográficos sobre la parte del IMPERIO MARROQUI que ha sido teatro de la última guerra con España. Palma de Mallorca.

1.861

PASTOR Y LOPEZ, Pascual.: Topografía físico-médica de VALLADOLID. Ed. Santarén. Valladolid.

SAlgado VAldes, M. y Perez Doblado, J.: Topografía médica de las parroquias de SAN Pedro y San Justo. La España Médica. T. VI. Págs. 441-42; 457-59; 467-72; 490-91; 507$08 ;$ y $522-24$

1.862

Velilla E InSA, Sebastián.: Monografía de la ciudad de CASPE y sus baños de Fonté. Imp. Juan Olivares. Barcelona.

1.863

ARnUS, Manuel.: Historia topográfica, química y médica de LA PUDA DE MonTSERRAT. Imp. del Diario de Barcelona. Barcelona.

1.864

Busto y Blanco, F. Del.:Topografía médica de las IsLAS CANARIAS. Imp. de la Andalucía. Sevilla.

PRADO, Casiano de.: Descripción física y geológica de la provincia de Madrid. Imp. Nacional. Madrid.

\subsection{7}

NuÑEZ, Juan José.: Descripción topográfica del pueblo de JAMILENA. Manuscrito.

OTERO, Ramón.: Apuntes para servir al estudio de la geografía médica de GALICIA. Imp. Rubial. Santiago de Compostela.

1.869

MARTINEZ Y REGUERA, Leopoldo.: Reseña histórico-descriptiva de la noble, leal y patriótica ciudad de MonToRo. Imp. J.A. Barbado. Montoro. 


\section{LAS TOPOGRAFÍAS MÉDICAS: REVISIÓN Y CRONOLOGÍA}

1.870

ANONIMO.: Topografía médico-botánica de la SIERRA DE AYLLON. Manuscrito (RAMB).

1.871

MARTINEZ, Juan Nepomuceno.: Ensayo de topografía médica del Real Sitio de EL PARDO y su hidrogeología. Imp. Rojos. Madrid.

1.872

EsCORIHUEla.: Topografía médica de PoRTUGALETE. Madrid.

1.874

ANONIMO.: Geografía médica de GRAN CANARIA. Manuscrito (RAMB).

1.875

CORTAZAR, Daniel de.: Descripción física, geológica y agrológica de la provincia de CUENCA. Imp. Tello. Madrid.

PEREZ de ARCE, José M $\mathrm{M}^{\mathrm{a}}$.: Topografía médica de la villa de LOECHES. Consideraciones generales sobre los elementos que es preciso abordar en la práctica de los estudios médicotopográficos. Manuscrito (RANM).

1.876

ARRO.: Topografía Médica de CALDAS DE MALVELLA. Manuscrito (RAMB).

1.877

Aguado y Morari, Francisco.: Memoria Médico-Topográfica de la villa de PozUELO DE ALARCON. Imp. Zaragozano. Madrid.

1.878

PESET Y VIDAL, J.B. Topografía médica de VALENCIA y su zona, o apuntes para una medicina práctica valenciana. Imp. Ferrer. Valencia.

1.879

ANONIMO. Topografía médica de NAVAS DE PORQUERA Manuscrito (RAMB).

ANONIMO.. Topografia médica de QUINTANAR DEL REY. Manuscrito. (RAMB).

BASSOLS.: Topografía médica de OLOT. Manuscrito (RAMB).

DOMENECH.: Topografía médica de CUEVAS DE VERA Manuscrito (RAMB).

DE HERNANDEZ OÑATE.: Memoria médico-topográfica de ENCISO y descripción de la epidemia variológica de 1.878. Manuscrito (RAMB).

1.880

ANONIMO.: Topografía médica de SAN GINES DE VILASAR. Manuscrito (RAMB).

GONZALEZ, Manuel.: Sucinta idea de las ISLAS CANARIAS en general y de la Gran Canaria en particular, bajo el punto de vista médico. Madrid.

LAFUENTE Y PARDO, Enrique.: Apuntes para la memoria médico-topográfica de la villa de VALDEARENAS. Valdearenas.

OlIU.: Estudio topográfico-médico de SAN FELIU DE GUIXOLS. Manuscrito (RAMB). 


\section{JUAN CASCO SOLÍS}

1.881

ANONIMO. Topografía médica de TARRASA. Manuscrito. (RAMB).

OLIU.: Estudio topográfico médico de GERONA Manuscrito (RAMB).

1.882

Hauser, Ph..: Estudios médico-topográficos de SEVILLA. Edit. Tomás Sanz. Círculo Liberal. Sevilla.

IBAÑEZ.: Topografía médica de EGEA DE LOS CABALLEROS. Manuscrito (RAMB).

MANERO, Evaristo. Estudios sobre la topografía médica de ALICANTE. Imp. Carratalá..Alicante.

MARQues y CuSA, Luis.: Estudio médico-topográfico y estadístco de LERIDA. Imp. Misericordia. Lérida.

S. E. DE AMIGOS DEL PAIS. Alicante. Una residencia de invierno. Estudio meteorológico y médico de ALICANTE. Alicante.

1.883

ANTIGÜEDAD, Félix.: Estudio topográfico-médico de MEDINILLA. Manuscrito. (RAMB).

CASAS ABAD, S.: Topografía médica de HUESCA. Huesca.

GuILLEN y FOMINAYA, José, y RIAZA TORRES, E. Memoria médico-topográfica de la villa de ARGANDA DEL REY. Manuscrito (RANM).

Oliu Pages, F.R.: Estudio topográfico-médico del VALLE DEL RonCAL. Manuscrito.(RAMB).

Trullas Soler, M.: Topografía médica de BuRGuillos. Manuscrito. (RANM).

1.884

ANONIMO.: Topografía médica de BELORADO. Manuscrito.(RAMB).

ANONIMO.: Topografía médica de LEON. Manuscrito(RAMB).

ANONIMO.: Topografía medica de MONREAL DE ARIZA Manuscrit(RAMB).

ANONIMO. Topografía médica de OLIVA DE MERIDA. Manuscrito. (RAMB).

ANONIMO.: Topografía médica de SANTANDER. Manuscrito (RAMB).

VIETA CANDURAS, Antonio.: La villa de AZAGRa bajo el punto de vista sanitario. Imp. M. Pallé. Calahorra.

1.885

ANONIMO.: Topografía médica de MANZANARES. Manuscrito. (RAMB).

ANONIMO.: Topografía médica de VILLAMURIEL DE CERCADO. Manuscrito. (RAMB).

MARTINEZ y MARTINEZ, Félix.: Topografía médica de la villa de MOGENTE y su zona. Manuscrito. (RAMB).

Montequi y GonZalez, Ricardo.: Bosquejo topográfico-médico de CANDELARIO. Imp. E. de la Riva. Madrid.

1.886

AlCAZAR, Rufino. Topografía médica de TARANCON. Manuscrito. (RAMB).

ANONIMO.: Topografía médica de ARROYOMOLINOS DE MONTANCHEZ. Manuscrito (RAMB)

ANONIMO.: Topografía médica de HoCAS NORTE-LUZON. Man. (RAMB).

ANONIMO.: Topografía médica de PALMA DE MALLORCA. Man. (RAMB).

ANONIMO.: Topografía médica de PUEBLA DE MoNTALBAN. Manuscrito.(RAMB).

ANONIMO.: Topografía médica de SEO DE URGEL. Barcelona. 


\section{LAS TOPOGRAFÍAS MÉDICAS: REVISIÓN Y CRONOLOGÍA}

ANONIMO.: Topografía médica de TINEO. Manuscrito. (RAMB).

GRANDA y GONZALEZ, Restituto. Memoria histórico-médico topografica de la leal villa de EL ESCORIAL y su término. Madrid.

IGLESIAS DIAZ, Manuel. Programa razonado de la Geografía Médica de ESPAÑA. Imp. Enrique Teodoro. Madrid.

TORRES Y TORNES, C.: Estudio topográfico-médico de SEGORBE. Castellón.

1.887

Aluja, A.M.: Topografía médica de REUS. Reus.

Compaired y CABOdEVILla, Celestino. Topografía médica de Estella y del partido médico-quirúrgico de VILLATUERTA. Navarra. Madrid.

1.888

Bernat y TABUEnCA,J.: Apuntes de topografía médica de ARAgon. Revista de Sanidad Militar, T. I y II.

LEON, Federico.: Datos para la estadística médica de la VEGA DE SAN MATEO. Imp. J.B. Planas. Barcelona.

Perez y Gimenez, Nicolás.: Estudio físico. Médico y social de la comarca de La Serena en general y de la villa de CABEZA DEL BUEY en particular. Tip. «La Económica». Badajoz.

SusAETA, Félix: Apuntes para un estudio médico-topográfico de VITORIA y su distrito municipal. Imp. La Ilustración. Vitoria.

1.889

ANONIMO.: Topografía médica de TREMP. Manuscrito (RAMB).

Eznariaga E IgLESIAS, Aniceto. Reseña médico-topográfica de ALCALA DE HENARES. Biblioteca de la Revista. de Sanidad Militar. Tip. Ricardo Fe. Madrid.

FRANQUESA Y SIVILla, Antonio: Topografía médica de MATARo y su zona. Barcelona.

GARCIA DUARTE, R. Topografía médica de GRANADA. Granada.

DE HeRnANDEZ OÑATE: Topografía médica y estadística demográfica de LoGROÑo. Logroño.

MELCIOR y FARRE, Victor. Topografía médica de MANRESA. Man.(RAMB).

PUJADAS SERRATOSA, Ramón: Recopilación de algunos apuntes para una memoria médico-topográfica de SENTMENAT. Barcelona.

Sanchez Santana, Esteban. Residencia invernal de AliCANTE. Tip. V. Botella. Alicante.

1.890

LaCalle Hernandez, Anastasio de: Memoria médico-topográfica de la villa de VALDEMORO. Tip. G. Pedraza. Madrid.

Mingo Alamo, Esteban de: Apuntes higiénicos de la villa de ALEDO. Imp. Casa de los Secretarios.Barcelona.

Vergara GARCIA, Eugenio Topografía médica de SEPULVEDA. Sepúlveda.

1.891

CORREA FERnANDEZ, Antonio: Ensayo de topografía médica de la provincia de LuGo. Imp. El Regional. Lugo.

GIBERT. Topografía médica de VILASECA DE SOLCENo. Barcelona. 


\section{JUAN CASCO SOLÍS}

MontAldo y PEIRO, Federico: Estudios topográfico-médicos de la localidad e histórico-médicos y clínicos de la epidemia de cólera que sufrió CARTAGENA en 1.885. Imp. R. Alvarez, Madrid.

RARNA.: Topografía médica de GARCIA. Manuscrito. (RAMB).

1.892

HERNANDEZ BRIZ, Baltasar: Estudios climatológicos y topográfico-médicos del Real Sitio de SAN LORENZO, llamado comunmente de El EsCORIAL. Madrid.

PUIG SARDO, Pedro: Topografía médica de SABADEll. Manusc. (RAMB).

SANTIAGo VILA, Felipe. Estudio topográfico-médico de TORTOSA y su término. Manuscrito. (RAMB).

1.893

LOPEZ SACCONE, Luis: Apuntes médico-geográficos sobre la ISLA DE FERNANDO POO y consideraciones acerca del paludismo como enfermedad predominante del país. Madrid.

NAVARro SABATER, Elías. Apuntes para la topografía médica de ALBACETE. Albacete.

1.894

ANONIMO: Topografía médica de MANRESA. Manuscrito. (RAMB).

CARRERAS: Topografía médica de CASTELLTERSOL. Manuscrito (RAMB).

GonZAlez del CASTILlo, Pelegrín, y LuIS Y TOMÄS, Francisco de.: Memoria higiénicosanitaria de LOGROÑO. Manuscrito (RANM).

Paredes,V. y Rosado, J.A.. Memoria Higiénica de Plasencia. Plasencia.

PIÑUela, Francisco de Paula.: Memoria topográfica, hidráulica, médica y política de la villa de EL MOLAR. Manuscrito (RANM).

1.895

ANONIMO. Topografía médica de La HorCAJADA. Manuscrita (RAMB).

Verges y Vernis, Pedro.; Topografía médica de CASTELLAR DEL VALLES. Imp. La hormiga de oro. Barcelona.

PaRdo y GonZalez, Felipe. Topografía médica de CARRASCAL DEL RIO. Imp. Jorge Montero. Valladolid.

1.896

ANONIMO: Topografía médica de ESPLUGAS DE FRANCOLI. Man (RAMB).

ASOCIACION MEDICO-FARMACEUTICA DE NAVALCARNERO: Geografía médica española: Distrito de NAVALCARNERO: Datos para un estudio médico-climatológico. Imp. del Hospicio. Madrid.

1.897

Bove Y PIQUe, Emilio: Topografía médica de SALLENT. Manuscrit (RAMB).

De la CRuZ Aragon, Francisco.: Datos para el estudio médico topográfico de la villa de BRUNETE. Madrid.

1.898

AlBANELlos, Braulio: Algunas consideraciones generales relativas a la ciudad de LoGROÑO. Actas y Memorias del IX Congreso Internacional de Higiene y Demografía. Madrid. 1.898. T.III. págs 278-302. 


\section{LAS TOPOGRAFÍAS MÉDICAS: REVISIÓN Y CRONOLOGÍA}

Alcazar Rufino: Memoria benéfico-sanitaria de TARAnCon. Actas y Memorias del IX Congreso Internacional de Higiene y Demografía. Madrid. 1.898. T.III, págs. 302-313.

JUAN E. BLANES, Vicente. Apuntes para el estudio médico de la topografía y atmosferología de la provincia de ALMERIA y del clima de su capital como estación de invierno. Actas y Memorias del IX Congreso Internacional de Higiene y Demografía. Madrid.1.898. Tomo III págs. 175-178.

Macho y Tome, A. y Garcia Ortiz, B. Memoria sanitaria del partido judicial de SALDAÑA. Actas y Memorias del IX Congreso Internacional de Higiene y Demografía. Madrid, 1.898. Tomo III,págs.196 y sgtes.

MARTINEZ MARTinez, Félix. Topografía médica de MogenTE.

Navarro Garcia. Topografía médica de la villa de CocA. Actas y Memorias del IX Congreso Internacional de Higiene y Demografía. Madrid 1.898. TomoII. P.195.

\subsection{9}

ANONIMO. Topografía médica de VILLAFRANCA DEL PANADES. Manuscrito. (RAMB).

LAREDo,I. Datos para el estudio médico-topográfico de PONFERRADA. Astorga.

Lorenzo BrIEgA, Abelardo: Datos médico-topográficos de CIUDAD RODRIGO. Imp. Cuadrado. Ciudad Rodrigo.

1.900

Diaz SANTA Olalla, Ildefonso.: Estudio sobre la viruela y descripción de la epidemia de dicha enfermedad en BRIVIESCA, en los años 1.897 a 1.899, con algunos datos de topografía médica de la expresada ciudad.. Imp. Polo. Burgos.

GONZALEZ BALAGUER, Domingo. Indice razonado para un estudio topográfico médico de la ciudad de BARCELONA. Barcelona.

XALABARDER, Eduart. Notas demográficas referentes a la morbositat y mortalitat a CALDAS DE MONTBUY. Imp. Jaume Josep. Granollers.

\section{TM DEL SIGLO XX}

1.901

ANONIMO: Apuntes para el estudio de la topografía médica de JEREZ DE LA FRONTERA. Jerez de la Frontera.

Falp Plana, J. Topografía médica de Solsona y distritos adyacentes (Clariana, Llovera, Rinen, Navès). Barcelona.

NiÑo Y ENCINAS, José: Estadística demográfica de la villa de ANTIGÜEDAD ((Palencia). Biblioteca Médica Española. Madrid.

PASSERAT DE LA CHAPElle, C.: Reflexiones generales sobre la isla de MENORCA. Mahón

VILA. Topografía médica de ToRTOSA. Manuscrito (RAMB).

1.902

ANONIMO: Topografía médica de PUIGCERDA. Manuscrito (RAMB).

ANONIMO: Geografía médica de la provincia de SANTANDER. Manuscrito (RANM).

GONZALEZ CASTRO, José: Estudio clínico de la epidemia de fiebre tifoidea acaecida en GUIJO DE SANTA BARBARA (Cáceres) en 1.889, precedida de la Topografía Médica de esta villa. Manuscrito (RAMB).

HAUSER, Ph.: MADRID bajo el punto de vista médico-social. Madrid. 


\section{JUAN CASCO SOLÍS}

1.903

TuIXAns Pedragosa, Joaquín: Apuntes topográficos médicos de BADALONA. Imp. J. Castellanos. Barcelona.

1.904

ANONIMO. Topografía médica de MARTORELL. Manuscrito (RAMB).

ANONIMO: Topografía médica de PRAT DE LLOBREGAT. Manus.(RAMB).

De LlOREnS y GallarT, Ignacio.. Topografía médica de CALAF. Imp. Elzeviriana de Borrás y Mestre. Barcelona.

LOPEZ PALACIOS, Félix. Apuntes para el estudio médico-topográfico de CANTALOJAS. Manuscrito (RANM).

VERGARA: Topografía médica de SAN SALVADOR DEL VALLE. Manuscrito. (RAMB).

1.905

ANONIMO: Geografía médica del partido judicial de BELORADO. Imp. J. Montero. Valladolid.

FISAC, Gaspar. Topografía médica de DAIMIEL y su partido. Manuscrito (RANM).

SANCHEZ ReCiO, Máximo: Datos para el estudio médico-topográfico de ALDEANUEVA DEL CAMINO. Imp. V. Escalante. Plasencia.

TOMÁS Y TOMÁs, José: Geografía médica de JUMILLA.

Yriagaray, Fermín: Topografía médica del VALLE DEL BAZTAN. Imp. N. Aramburu. Pamplona.

1.906

Calvo Dominguez, José: Geografía médica de CARMona. Imp. Escuela Prof. de Artes y Oficios Sevilla.

GARRIGA y PUIG, Bonfilio. Topografía médica de SAN CUGAT DEL VALLES. Barcelona.

MarC ANGLADA, L.: Apuntes para la topografía médica y demografía de ESPLUGAS DE FRANCOLI. Manuscrito (RAMB).

Pallas VAlls, Pedro.: Topografía médica de MANRESA. Barcelona.

RUEDA Y CORRAL, Pedro. Geografía médica del partido de SALVATIERRA.

1.907

ANONIMO: Geografía médica del concejo de BIMENES. Manuscrito (RANM).

ANONIMO: Topografía médica del concejo de LENA. Manuscrito. (RANM).

ANONIMO: Reseña médico-topográfica del concejo de TINEO. Manuscrito(RANM).

Dominguez Alonso, Severino: Datos para el estudio médico-topográfico de la villa de BUDIA. Tip. Antero Concha.

SALAZAR: Topografía médica del valle de REOCIN. Torrelavega.

1.908

ANONIMO: Topografía médica de MAJADAHONDA. Manuscrito (RANM).

MoRENTE y CEJo, María del Rocío. Geografía, topografía e historia de TALAVERA LA REAL. Badajoz.

1.909

ANONIMO: Topografía médica de CASTRILLON. Manuscrito. (RANM). 


\section{LAS TOPOGRAFÍAS MÉDICAS: REVISIÓN Y CRONOLOGÍA}

ANONIMO: Topografía médica del concejo de OVIEDo. Manuscrito. (RANM).

GarCia Alonso, Dionisio: Geografía médica de VILLAVIEJA y de Las Alquerías. Imp: Almaraz. Salamanca.

HERNANDEZ BRIZ, Baltasar: Geografía o topografía médica de la SIERRA DE GUADARRAMA. Tip. N.Millán. Madrid.

1.910

CARACUEl y Farrugia, Salvador. Topografía médica de NAVALAGAmElLA. Manuscrito.(RANM).

MontANya I SANTAMARIA, Fco. X.:Topografía médica de PONS y su comarca. Lleida.

1.911

ANONIMO: Geografía médica de VILLAVICIOSA DE ODON. Manuscrito.(RANM).

GONZÄLEZ VALDES: Topografía médica del concejo de OVIEDO. Imp. Hijos de Tello. Madrid

MuÑoz-Orea Pollo, Manuel. Datos para la topografía médica de SALAMANCA:Imp. Gabañach. Barcelona.

1.912

ANONIMO: Topografía médica de ALCOVER. Tarragona.

ANONIMO: Geografía médica de TORTOSA. Manuscrito (RANM).

MARTINEZ y MARTINEZ, Valentín. Exposición de algunos datos referentes al pueblo de PARLA y casos clínicos. Manuscrito (RANM).

1.913

ANONIMO. Geografía médica de MAHON y su término. Manuscrito.(RANM).

ANONIMO: Geografía médica de la villa de AgUAVIVA. Manuscrito.(RANM).

ANONIMO: Estudio médico topográfico del concejo de Tineo. Man.(RANM).

ANONIMO: Topografía médica de SANTA MARIA DE NoREÑA. Man. (RANM).

HAUSER, Ph.: La geografía médica de la PENINSUla IBERICA. Edit. Edmundo Arias. Madrid.

SuAREZ DE Figueroa y GAZEAME, José: Estudio higiénico y médico del partido judicial de TORTOSA. Barcelona.

Villalain, José de. Topografía médica de AVILES. Imp Hijos de Tello.Madrid.

1.914

ANONIMO: Geografía médica del concejo de MuROS. Muros.

CARACUEl y FARRUGia, Salvador: Topografía médica de VILLAMANTA. Manuscrito (RANM).

MASCARO Y CASTAÑER, José Ma .: Topografía médica de BAÑOLAS. Gerona.

PONS MARQUES, Lorenzo: Geografía médica de MAHON y su término. Barcelona.

RiUS y TARRAgO, Agustín: Topografía médica de SABADELL. Barcelona.

VILAR y FERRAN, J.: Topografía médica de la villa de VIELLA y en general del valle de Arán. Manuscrito (RAMB).

1.915

Batlle CiBit, G.: Topografía médica de ToRRoJa. Manuscrito (RAMB).

Duran Martinez, José. La topografía médica de MELIANA. Valencia 


\section{JUAN CASCO SOLÍS}

Portola Puyos, Felipe: Topografía médica del concejo de PONGA. Tip. Hijos de Tello. Madrid

Villalain, José de: Topografía médica del concejo de LuARCA. Tip. Hijos de Tello. Madrid.

1.916

ANONIMO: Monografía de ONTENIENTE. Manuscrito (RANM).

ARIET BARBERIS, Antoni: Topografía médica de VILADRAU. Barcelona.

1.917

ANONIMO: Topografía médica del concejo de Gozon. Manuscrito. (RANM)

ANONIMO: Topografía médica de DEGAÑA. Manuscrito. (RANM).

ANONIMO: Bosquejo de Geografía médica e histórica del partido judicial de BRIVIESCA. Manuscrito.(RANM).

ANONIMO: Geografía médica de LA ESCALA y FIGUERAS. Manuscrito (RANM).

ANONIMO: Apuntes para una Geografía Médica de VILLAMANTILLA. Manuscrito(RANM).

ANONIMO. Geografía médica de la Provincia de SORIA. Manuscrito. (RANM).

ANONIMO: Geografía médica de ALCIRA. Manuscrito (RANM).

VILAR y FERRAN, J.: Topografía médica del distrito municipal de VILLANUEVA DE LA CAÑADA, ó La Espernada. Est. Tip. El Liberal. Madrid.

1.918

CASAS DIEZ, Angel: Geografía médica de HONDONADA DE CAMPOS. Manuscrito (RANM)

PORTOLA PUYOS, Felipe. Topografía médica del concejo de GIJON. Imp. El Liberal. Madrid.

1.919

ANONIMO: Topografía médica del concejo de CARREÑo. Manuscrito (RANM).

1.920

CASAnOvas. Topografía médica de AgRAMUNT. Manuscrito (RAMB).

MANZANO, Marcelo: Datos para la geografía médica de CIUDAD RODRIGO. Imp. V. Cuadrado. Ciudad Rodrigo.

VILAR Y FERRAN, J. y CARACUEL Y FARRUGIA, Salvador: Topografía médica del distrito municipal de VILLA DEL PRADO. Tip. El Liberal. Madrid.

1.921

VILAR Y FERRAN, Joaquín: Topografía médica del concejo de CABRALES. Madrid.

1.922

CARAcuel y Farrugia, S. y VILAR y Ferran, J.: Topografía médica del distrito municipal de Mostoles. Tip. El Liberal. Madrid.

1.923

ANONIMO. Topografía médica de LEGANËS y su término. Manuscrito. (RANM).

Cervellada CAStro, A.: Topografía médica de BURJASOT. Valencia.

Jove y CANELla, José Ma .: Topografía médica del consejo de SAN MARTIN DEL REY AURELIO. Imp. Ciudad Lineal. Madrid.

VILLALAIN, José de: Topografía médica del concejo de ILLAS. Imp. Ciudad Lineal. Madrid. 


\section{LAS TOPOGRAFÍAS MÉDICAS: REVISIÓN Y CRONOLOGÍA}

1.925

GARCia SAEZ-DiEnTE, José: Topografía médica de LA LINEA DE LA CONCEPCION. Cádiz.

Jove y CANELla, José Ma .: Topografía médica del concejo de LANGREO. Imp. Ciudad Lineal. Madrid.

Plaza y Ballesteros, Arsenio. Topografía médica de TAlamanca Del Jarama. Imp. Ciudad Lineal. Madrid.

Villalain, José de: Topografía médica del concejo de CoRVERA DE ASTURIAS. Imp. Ciudad Lineal. Madrid.

1.926

ANONIMO: Topografía médica de TORREDEMBARRA. Manuscrito (RAMB).

SURIOL: Topografía médica de CALDAS DE MONTBUY. Manuscrito (RAMB).

1.927

Grau Bono, V.: Topografía médica de TABERNES DE VALLDIGNA. Alcira.

HERNANDEZ BRIZ, B.: Geografía o topografía médica del partido municipal de SAN LORENZO. Imp. Ciudad Lineal. Madrid.

Jove y Canella, Jose Ma .: Topografía de LaViana. Imp. Cosano. Madrid.

NAVARRo SOlER, Vicente: Topografía médica de BENETUSER. Imp. José Olmos. Valencia

PICABEA, Carlos: Topografía médica del término municipal de TORRELODONES. Imp. Ciudad Lineal. Madrid.

1.928

ANONIMO: Topografía médica del término municipal de RIOSA. Manuscrito (RANM).

PEDRERO y VALleS, J.: Topografía de CAMPORREDONDO. Manuscrito (RANM).

Sau y Santalo, J.: Topografía médica de la comarca de CAmprodon. San Felíu de Guixols.

1.929

ANONIMO: Topografía médica de NAVARCLES. Manuscrito (RAMB).

Gomez Plana y CONTE, José: Topografía, urbanismo e higienización del distrito médico de La PALMa del Barrio de la Viña. Cádiz.

1.930

ANONIMO: Estudio topográfico médico del concejo de SIERO. Manuscrito (RANM).

ARMANGUE Tuset, Josep: Crítica y comentarios a la topografía médica de la comarca de CAMPRODON del dr. Sau y Santaló. Barcelona.

Martinez Hidalgo, Eduardo. Topografía, Climatología y Demografía médica de la villa de Albalate de las Nogueras. Cuenca.

SANTOS PUJOL, Francisco: Geografía y topografía médica de CAMPORREAL. Manuscrito (RANM).

1.932

Caballero y Villadea, Sergio: Geografía médica de Pezuela de Torres. Imp. Cosano. Madrid. 


\section{JUAN CASCO SOLÍS}

FERNANDEZ, Valentín: Topografía médica del consejo de TAPIA DE CASARIEGO. Imp. Cosano. Madrid.

Jove y CANELla, José $\mathrm{M}^{\mathrm{a}}$. y AlONSO, Luis: Topografía médica del término municipal de SOBRESCOBIO. Imp. Cosano. Madrid.

Villalain, José de: Topografía médica del concejo de Soto DEL BARCo. Imp. Cosano. Madrid.

1.933

ANONIMO. Topografía médica de PATONES. Manuscrito (RANM).

Alvarez SierRA, José: Geografía médica de ChAMARTIN DE LA RoSA. Imp. Cosano. Madrid.

FERNAN PEREZ, Juan: Topografía médica del concejo de NAVAS. Manuscrit (RANM)

1.934

ANONIMO: Topografía médica del concejo de CARAVIA. Manuscrito. (RANM).

ANONIMO: Topografía médica de CANGAS DE ONIS. Manuscrito. (RANM).

ANONIMO: Topografía médica de CoLUNGA. Manuscrito. (RANM).

ANONImo: Topografía médica de Colmenar VIEJo. Manuscrito. (RANM).

GonZalez MonTERo, Pedro: Topografía médica de CHINCHON. Manuscrito. (RANM).

1.936

ANONIMO: Geografía médica de GUADARRAMA. Manuscrito. (RANM).

ANONIMO: Geografía médica de ALCALA DE HENARES. Manuscrito (RANM).

JunCEDA, Eladio: Topografía médica del concejo de NAVIA. Imp Cosano. Madrid.

VALLS I BRIQUETES, Orenci: Topografía médica D'ESPARRAGUERA. Esparraguera..

1.940

ANONIMO: Topografía de ARANJUEZ. Manuscrito. (RANM).

ANONIMO: Geografía y topografía médica de PRAVIA. Manuscrito (RANM).

Plaza BALlesteros, Arsenio: Geografía, topografía y climatología medica de TORRELAGUNA. Manuscrito. (RANM).

1.941

ANONIMO: Topografía médica de PILONA. Manuscrito. (RANM).

CASTILlo DE LuCAS: Geografía médica de EL ALAMO. Madrid.

1.942

ListaR y DE LA ChIVA, José: Topografía médica de MonTANEJos. Manuscrito. (RANM).

1.943

Gomez Domingo, J.: Geografía médica de FuENCARRAL. Manuscrito (RANM).

Mozote Sagardia, José: Topografía médica del término municipal de PINTO. Imp. Cosano. Madrid

MurGa Y SERRET, Jorge: Geografía médica de NAVALCARNERO. Manuscrito. (RANM).

1.944

ANONIMO: Topografía médica de MIERES. Manuscrito (RANM). 


\section{LAS TOPOGRAFÍAS MÉDICAS: REVISIÓN Y CRONOLOGÍA}

1.945

ANONIMO: Geografía médica del concejo de VILLAVICIOSA. Manuscrito (RANM).

ANONIMO: Topografía médica de CASO. Manuscrito. (RANM).

Box Maria CosPedal, Antonio: Geografía médica de CADALSO DE LOS VIDRIOS. Imp. Cosano, Madrid.

1.946

AlVAREZ SIERRA, José: Geografía y topografía médica de CASTROPOL. Imp. Cosano. Madrid.

CARdenas, Consuelo: BRUNETE (La obra «Regiones Devastadas») Man. (RANM).

VAQUeRo HeRnáNDEZ, Antonio: Geografía médica de CANILLAS. Manuscrito. (RANM).

1.947

ANONIMO: Topografía médica de ALPEDRETE. Manuscrito. (RANM).

ANONIMO: Geografía médica del término de GUADALIX DE LA SIERRA. Manuscrito. (RANM).

Sanchez Morate, J. y Azofra Cervera, Lorenzo: Topografía médica de Getafe. Imp. Cosano Madrid.

1.948

ANONIMO: Geografía, climatología y topografía médica de MADRID, capital de España. Manuscrito. (RANM).

GARCIA Y GARCIA MiÑón, Julián.; Geografía y topografía médica del Real Sitio de ARANJUEZ. Imp. Cosano. Madrid.

1.951

PARDO CANALÍS, Julio: Geografía y topografía médica de LA GARRIGA. Su paisaje. Sus alrededores. Edit. Alpina. Granollers.

1.952

ANONIMO: Geografía y topografía médica del término municipal de MADRID. Manuscrito. (RANM).

1.953

ANONIMO: Geografía médica del termino municipal de GUADALIX DE LA SIERRA.

Manuscrito. (RANM).

Acuña Bautista, Alejandra, y Muro Fernandez Cavada, Antonio. Geografía médica de CIEMPOZUELos. Imp. Cosano. Madrid.

1.955

FIEYRE AMER, Enrique: Topografía médica de CABRALES. Manuscrito. (RANM).

1.956

Perez Gomez, Francisco: Topografía médica del término municipal de CASO.

Imp. Cosano. Madrid.

1.958

Garcia Ramos, E. y Amberes Miguélez, Eduardo: Geografía médica del término municipal de EL RoSARIo. Edit. J. Régulo. Santa. Cruz de Tenerife. 


\section{JUAN CASCO SOLÍS}

1.959

Cabrero Gomez, Francisco: Topografía médica de Villarejo de SALVANES. Imp. Cosano. Madrid.

Garcia Ramos, E. y Amberes Miguelez, E. Geografía médica del término municipal de FASNIA. Imp. Católica. Santa Cruz de Tenerife.

Martin Aragon: Datos curiosos de la villa de La Puebla de Montalban. La Puebla de Montalbán.

1.961

Casco Arias, Juan. Geobiografía e historia de Quintana DE LA SERENA. Edit. Prensa Española: Madrid.

1.964

JiMENEZ HerRero, Fernando: Geografía médica de SALAS. IMP. Cosano. Madrid.

1.968

ANONIMO: Estudio Médico-Social de la provincia de CACERES. Manuscrito (RANM).

\section{T:M: SIN FECHA}

MuÑIZ PIZADA. Topografía del concejo de MIERES y su comarca.

REÑE. Estudi topográfico- médico de RUPIÁ.

SALARICH I Verdaguer, Joaquín. Estudio topográfico médico del llano de VICH. Biblioteca M. S. Salarich. (circa 1.882).

TUIXANS PEDRAgosa, Joaquín: Apuntes para una topografía médica de MoNTSERRAT. Manuscrito (RAMB) (circa 1.905).

ANONIMO: Estudio médico topográfico de CERVERA DEL RIO ALHAMA y su distrito. (¿Años veinte?)

ANONIMO: Topografía y Geografía médica de RIBADESELLA. 